\title{
Ultra-High Pressure Water Jet: Baseline Report; Greenbook (Chapter)
}

\author{
RECEIVED \\ FLD 231998 \\ Topical Report \\ July 31, 1997 \\ OSTI
}

\section{0}

Work Performed Under Contract No.: DE-FC21-95MC32260

For

U.S. Department of Energy

Office of Environmental Management Office of Technology Development 1000 Independence Avenue Washington, DC 20585
U.S. Department of Energy Office of Fossil Energy Federal Energy Technology Center Morgantown Site P.O. Box 880

Morgantown, West Virginia 26507-0880 


\section{Disclaimer}

This report was prepared as an account of work sponsored by an agency of the United States Government. Neither the United States Government nor any agency thereof, nor any of their employees, makes any warranty, express or implied, or assumes any legal liability or responsibility for the accuracy, completeness, or usefulness of any information, apparatus, product, or process disclosed, or represents that its use would not infringe privately owned rights. Reference herein to any specific commercial product, process, or service by trade name, trademark, manufacturer, or otherwise does not necessarily constitute or imply its endorsement, recommendation, or favoring by the United States Government or any agency thereof. The views and opinions of authors expressed herein do not necessarily state or reflect those of the United States Government or any agency thereof. 


\section{ULTRA-HIGH PRESSURE WATER JET}

TABLE OF CONTENTS

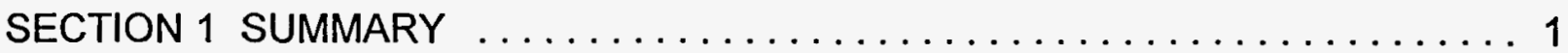

TECHNOLOGY DESCRIPTION $\ldots \ldots \ldots \ldots \ldots \ldots \ldots \ldots \ldots \ldots \ldots$

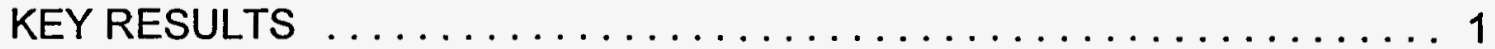

SECTION 2 -TECHNOLOGY DESCRIPTION $\ldots \ldots \ldots \ldots \ldots \ldots \ldots \ldots \ldots \ldots$

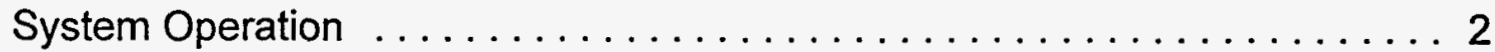

SECTION 3 - HEALTH AND SAFETY EVALUATION $\ldots \ldots \ldots \ldots \ldots \ldots \ldots$

General Health and Safety Concerns $\ldots \ldots \ldots \ldots \ldots \ldots \ldots \ldots$

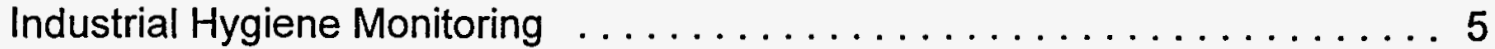

Human Factors Interface ......................... 9

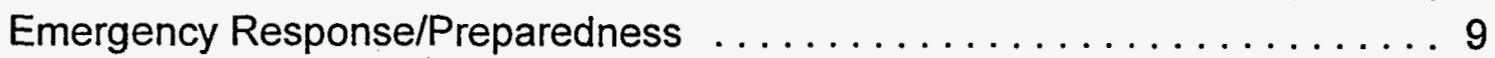

SECTION 4 - TECHNOLOGY APPLICABILITY .................. 10

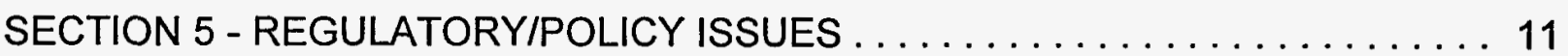

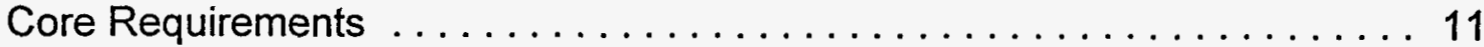

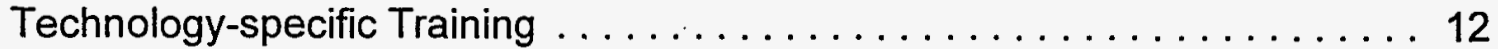

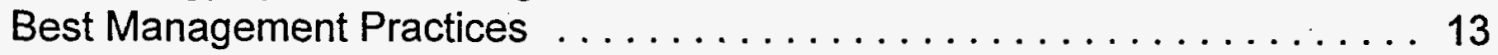

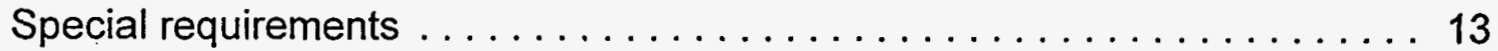

Core Training Requirements $\ldots \ldots \ldots \ldots \ldots \ldots \ldots \ldots \ldots \ldots \ldots \ldots \ldots \ldots$

Special Training . ......................... 14

Best Management Practices Training $\ldots \ldots \ldots \ldots \ldots \ldots \ldots \ldots \ldots$

SECTION 6 - OPERATIONAL CONSIDERATIONS AND

RECOMMENDATIONS ......................... 14

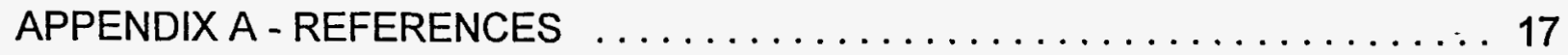

APPENDIX B - INDUSTRIAL HYGIENE DATA $\ldots \ldots \ldots \ldots \ldots \ldots \ldots \ldots \ldots$ 


\section{ULTRA-HIGH PRESSURE WATER JET HUMAN FACTORS EVALUATION}

\section{SECTION 1 - SUMMARY}

\section{TECHNOLOGY DESCRIPTION}

The ultra-high pressure waterjet technology was being evaluated at Florida International University (FIU) as a baseline technology. In conjunction with FIU's evaluation of efficiency and cost, this report covers the evaluation conducted for safety and health issues. It is a commercially available technology and has been used for various projects at locations throughout the country.

The ultra-high pressure waterjet technology acts as a cutting tool for the removal of surface substrates. The Husky ${ }^{\mathrm{TM}}$ pump feeds water to a lance that directs the high pressure water at the surface to be removed.

\section{KEY RESULTS}

The safety and health evaluation during the testing demonstration focused on two main areas of exposure. These were dust and noise. The dust exposure was found to be minimal, which would be expected due to the wet environment inherent in the technology, but noise exposure was at a significant level. Further testing for noise is recommended because of the outdoor environment where the testing demonstration took place. In addition, other areas of concern found were arm-hand vibration, ergonomics, heat stress, tripping hazards, electrical hazards, lockout/tagout, fall hazards, slipping hazards, hazards associated with the high pressure water, and hazards associated with air pressure systems. 


\section{SECTION 2 \\ TECHNOLOGY DESCRIPTION}

\section{SYSTEM OPERATION}

The ultra-high pressure waterjet technology was being evaluated at Florida International University (FIU) as a baseline technology. In conjunction with FIU's evaluation of efficiency and cost, this report covers the evaluation conducted for safety and health issues. It is a commercially available technology and has been used for various projects at locations throughout the country.

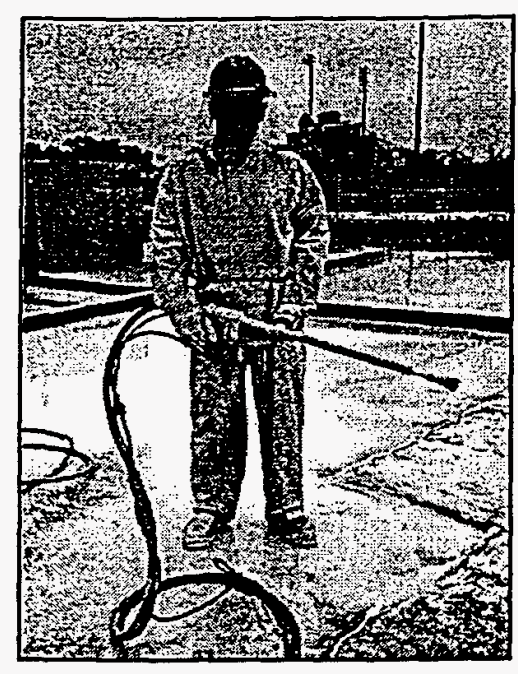

Figure 1- Operator and waterjet lance.
The Husky ${ }^{T M}$ is an ultra-high-pressure waterjet cutting tool. The pump is mounted on a steel tube frame which includes slots for transport by a forklift. Utility interface connections are located on the rear bulkhead. The husky also features an automatic shutdown for low oil pressure, high oil temperature, or low inlet pressure, an in-line water filter to remove particles larger than 5 microns, a safety valve to relieve system pressure when over-pressure conditions occur, a triplex high pressure pump, and red or amber sensor lights that illuminate for a shutdown condition.

The system requires a water supply of 6 gallons per minute. The pump inlet water is routed through a 5 micron water filter to the pump inlet check valves. During the intake stroke of the pump, water enters the cylinder. A the end of this stroke the inlet check valve closes. On the pressure stroke, the plunger pressurizes the water until the outlet check valve opens. At the end of the pressure stroke, the outlet valve closes and the cycle is repeated.

Placement of the Husky ${ }^{T M}$ must allow for a three foot clearance on all sides for operation and service access. At maximum continuous operation, the output volume is 7.2 gallons per minute with an output pressure of 40,000 psi. A diesel engine provides power for the system.

The operator of the waterjet did not encounter difficulties with equipment operation while dressed out in the appropriate PPE. The operator of the Husky ${ }^{T M}$ did experience some difficulty during

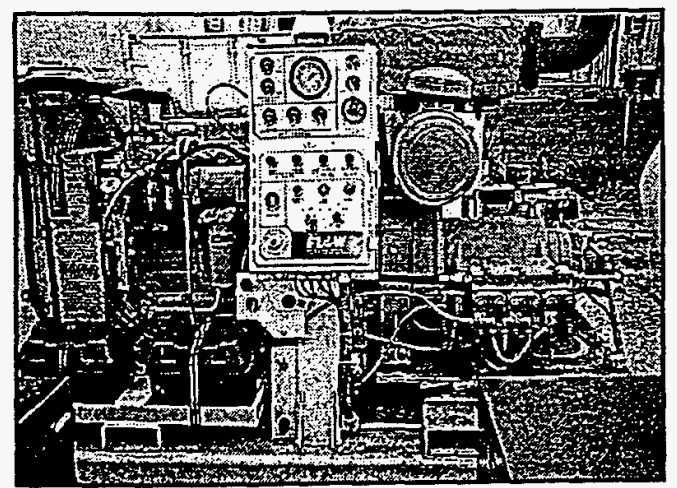

Figure 2 - The pump. 
maintenance activities due to decreased visibility and a decrease in tactile sensitivity in the hands/fingers. The technology did present a significant noise hazard. These as well as other safety and health factors will be discussed in greater detail in other sections of this report.

\section{SECTION 3 \\ HEALTH AND SAFETY EVALUATION}

\section{General Safety and Health Concerns}

Personnel where the ultra-high pressure water jet technology is being used need to be concerned with safety and health issues. Issues that personnel need to be cognizant of may be divided into two categories. Core issues are those that are based on current safety and health regulatory requirements. Best management practices are related to issues that are not based on current safety and health regulations but are key elements in preventing worker injury and illness on the job.

Safety and health issues of concern with the ultra-high pressure water jet technology included:

- Tripping hazards - the high pressure lines, water lines (a garden hose), and air lines needed to operate the equipment, while necessary, are tripping hazards, therefore, the need for stringent housekeeping must be evaluated.

- Electrical hazards - the electrical system in the Husky ${ }^{\mathrm{TM}}$ can present electrical hazards, therefore, the need for ground fault circuit interrupters and grounding must be evaluated. If there are any electrical sources in the area where the high pressure water is being used, they would be a hazard and would need to be deenergized in accordance with lockout/tagout procedures.

- Fall hazards - the Husky ${ }^{\mathrm{TM}}$ was located on a truck bed during the testing demonstration. The truck bed sat approximately four feet above the ground. This presented a fall hazard and the truck bed needs to have railings. In addition, the vertical ladder on the truck bed did not have any hand rails and therefore, did not allow the worker to maintain three points of contact while climbing. Hand rails need to be placed on the ladder.

- Lockout/Tagout - the user of the technology will need to develop a lockout/tagout program to assure there is not an accidental release of energy during maintenance/repair activities. 
- Heat stress - the operators of the waterjet and the pump were subjected to an increase in heat stress due to the need to utilize Anti-C PPE and /or splash (water resistant) PPE. The user will need to develop a heat stress program for the environment in which the technology is being used, taking into consideration any PPE that may need to be utilized.

Ergonomics - the user was subjected to some ergonomic stressors that need to be taken into consideration, such as, stooping, bending, twisting, kneeling, and lifting. The lance added a constant weight in the hands of the operator. This will add to the stress placed on the lower back and to the upper body. In particular, fatigue of the arms and upper body.

- Arm-hand vibration - the waterjet operator was subjected to arm-hand vibration while operating the equipment. The support handle on the lance was constructed of a hard rubber material. This placed increased stress on the hand. A softer material would place less pressure on the hand. The trigger on the lance for the waterjet was made of metal and was designed for single finger operation. This will put stress on the index finger and could lead to problems such as trigger finger. A trigger design that uses several fingers and is designed with a cushion over the metal would be a better choice.

- Whole-body vibration - the platform (truck bed) on which the Husky ${ }^{\mathrm{TM}}$ was mounted was a source of whole-body vibration during operation. The operator is required to stay with the pump and therefore, would be exposed to vibration throughout the day.

- Noise - the user is subjected to a significant amount of noise while operating the water lance. The operator of the Husky ${ }^{\mathrm{TM}}$ is also subjected to a significant amount of noise during operations.

- Dust - due to the wet operating environment, dust was not a significant problem during operation. The spread of contaminant, however, was of concern. The waterjet created a situation where grit (small pieces of water blasted concrete) were sprayed up to fifty feet from the point where the waterjet was in contact with the concrete. The water spray and the spray of concrete created a spread of contaminant that was evident on other surfaces and the PPE of the operator. Water run off was also a problem for the spread of contaminant. There is potential for dust to be left on the surface after the water dries and this can present an inhalation exposure if the dust is disturbed.

- Diesel Exhaust - the Husky ${ }^{\mathrm{TM}}$ uses a diesel engine for operation. If the pump was being used indoors, it could create an exposure situation for diesel fumes and of particular concern carbon monoxide. Even in an outdoor testing situation, 
such as the testing demonstration, depending on the wind direction, there is potential for exposure to the diesel fumes.

- Struck by hazards (from concrete) - The waterjet created a situation where grit (small pieces of blasted concrete) was sprayed up to fifty feet from the point where the waterjet was in contact with the concrete. The water spray and the spray of concrete created a spread of contaminant that was evident on other surfaces and the PPE of the operator. The flying pieces of concrete presented a severe eye hazard. A splash suit or a water resistant Anti-C suit would not provide enough protection against puncture from flying debris. A Saranex coated Tyvek or a level B PVC suit may be required. Additionally, safety glasses may not be protective enough and goggles need to be worn under a face shield.

- Slipping hazard - the water and water/concrete debris created an extremely slippery surface. This included not only the surface where the operator was working but adjoining surfaces as well.

- Compressed air - the use of compressed air created tripping hazards from the air line. In addition, there is the potential for injury from the compressed air itself or the air hoses if an accidental disconnect, rupture, or leak occurs.

- High pressure water - the use of high pressure water created tripping hazards from the water supply and discharge lines. In addition, there is potential for injury from the high pressure water jet or high pressure water lines if an accidental disconnect, rupture, or leak occurs. There is a severe hazard created by the water being discharged at the head of the lance. If the operator were to hit his/her leg, foot, or any other body part with the waterjet, there is potential for a severe laceration or even amputation.

- Communication - due to the noise generated by the technology during operation and the distance between the waterjet-lance operator and the pump operator, communication was difficult. Personnel working in the area should be familiar with and use hand signals when needed. If the lance is being used inside an enclosure and the pump is outside, radio communication is needed but would be difficult during operation due to the noise levels. In this case, other types of signals such as flashing lights may need to be employed.

\section{INDUSTRIAL HYGIENE MONITORING}

During the current testing demonstration with the high pressure water system, sampling was conducted for dust and noise. In addition, the wet-bulb globe temperature was 
monitored to evaluate heat stress. Observational evaluation was conducted for ergonomics, arm-hand vibration, and whole-body vibration.

Through general observational techniques the potential for ergonomic problems was evaluated during the testing demonstration. There is potential for muscle/back stress and/or injuries due to bending, twisting, and lifting associated with the setup, operation, maintenance, and decontamination of the equipment. The greatest potential for back stress is during operation of the lance. The operator was using the longest lance available and still had to stoop constantly to reach the surface and control the backpressure from the lance. There was stress placed on the upper body from operating the lance and stress on the legs from standing in one position for an extended period of time while maintaining the lance in the correct position with the backpressure being exerted.

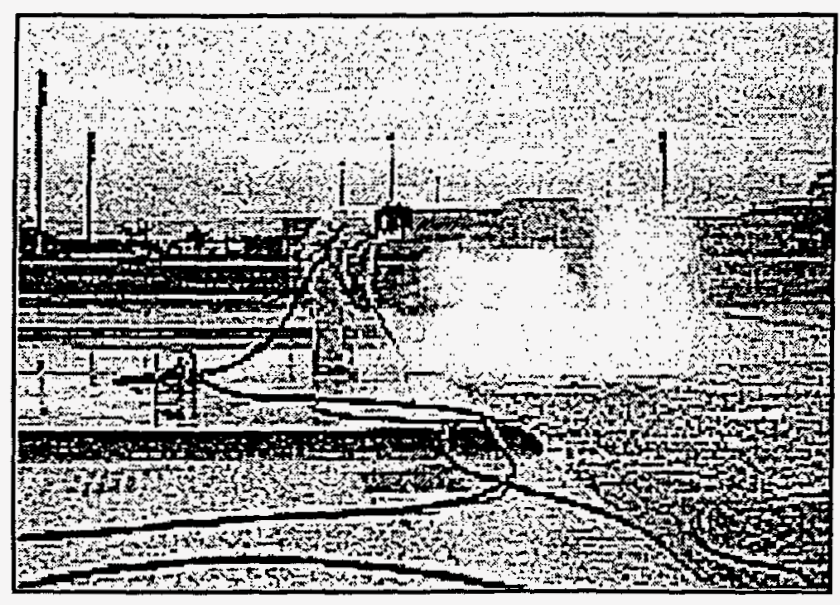

Figure 3- Waterjet in use.
During the testing demonstration armhand vibration was present. While armhand vibration was not quantitatively measured, it was readily apparent that there was exposure to arm-hand vibration during operation of the waterjet lance that could potentially cause problems such as Raynaud's syndrome. The support handle on the lance was constructed of a hard rubber material. This placed increased stress on the hand. A softer material would place less pressure on the hand. The trigger on the lance for the waterjet was made of

metal and was designed for single finger operation. This will put stress on the index finger and could lead to problems such as trigger finger. A trigger design that uses several fingers and has a cushion over the metal would be a better choice. Whole-body vibration was a concern for the operator of the Husky ${ }^{\mathrm{TM}}$ pump. The platform (truck bed) on which the pump was mounted vibrated constantly during operation.

Heat stress was monitored using a Quest QuestTemp ${ }^{\circ} 15$ Heat Stress Monitor. The wet-bulb globe temperature was used to determine the work/rest regimen in accordance with the American Conference of Governmental Industrial Hygienist (ACGIH) recommendations. The wet-bulb globe temperature was adjusted for the type of clothing, including PPE, that the worker was wearing.

In addition, the worker's blood pressure, pulse, and temperature were monitored throughout the day. No problems were encountered due to heat stress but the worker's comfort level was increased when not wearing the Anti-C PPE, Saranex coated Tyvek, 
or splash suit. While heat stress will be increased when wearing PPE, the overall heat stress response will vary from worker to worker. Each situation in which the current technology is used will need to be evaluated for the heat stress potential taking into consideration the wet-bulb globe temperature, PPE in use, physical condition of the worker, and amount of worker acclimatization.

Dust monitoring was conducted with a sampling train consisting of an SKC IOM Inhalable dust sampler coupled with a MSA Escort Elf air sampling pump. Pre- and post sampling calibration was accomplished using a BIOS International DryCal DC1 primary calibration system. Sampling filters were desiccated pre- and post sampling and weighed on a Denver Instrument Company A-200DS scale. Sampling was conducted in accordance with NIOSH method 0500.

Personal sampling was conducted on the equipment operator and the pump operator. Personal dust sampling results of $2.0 \mathrm{mg} / \mathrm{m}^{3}$ and $84.1026 \mathrm{mg} / \mathrm{m}^{3}$ for the water lance operator and $0.0 \mathrm{mg} / \mathrm{m}^{3}$ and $0.7874 \mathrm{mg} / \mathrm{m}^{3}$ were obtained for the pump operator. One of these values $\left(84.1026 \mathrm{mg} / \mathrm{m}^{3}\right)$ exceeds the Occupational Safety and Health Administration (OSHA) permissible exposure limit (PEL) and the ACGIH threshold limit value (TLV) of $15 \mathrm{mg} / \mathrm{m}^{3}$ and $10 \mathrm{mg} / \mathrm{m}^{3}$ respectively for total dust. There was not any visible dust generated during operation due to the wet environment inherent in the process. The extremely high value of $84.1026 \mathrm{mg} / \mathrm{m}^{3}$ appeared to be due to the accumulation of grit on the filter of the inhalable dust sampler. While not a dust problem, this illustrates the ability of the technology to spread contamination into the breathing zone of the operator. The grit itself could become an ingestion hazard. This indicated a potential need for PPE other than a face shield and safety glasses such as a full face respirator. A complete sampling plan for a site would need to be developed to include not only dust but other contaminants specific to the concrete decontamination project. See Appendix B for sampling data.

Personal noise monitoring was conducted using Metrosonic db-3100 data logging noise dosimeters. Calibration was conducted pre- and post monitoring using a Metrosonic CL304 acoustical calibrator. Monitoring was conducted on the Husky ${ }^{\mathrm{TM}}$ pump operator for 2.05 hours ( 123 minutes) and again for 7.86 hours (472 minutes) during operation of the waterjet system. Monitoring during this time showed a noise dose of $16.54 \%$ which gives an 8-hour time-weighted average (TWA) of $77.0 \mathrm{dBA}$ and $108.21 \%$ which gives an 8-hour TWA of $90.5 \mathrm{dBA}$. If the pump operator continued to have the same level of noise exposure during the 8-hour shift a projected 8-hour TWA would produce a noise dose of $64.37 \%$ or an 8 -hour TWA of $86.8 \mathrm{dBA}$ and $133.74 \%$ or an 8 -hour TWA of 92.1 $\mathrm{dB}$ respectively.

Monitoring conducted on the lance operator was conducted for 7.88 hours ( 473 minutes) during operation of the waterjet system. Monitoring showed a noise dose of $875.1 \%$ which gives and 8-hour TWA of $105.6 \mathrm{dBA}$. If the lance operator continued to 
have the same level of noise exposure during the 8-hour shift a projected 8-hour TWA would produce a noise dose of $1135.73 \%$ or an 8-hour TWA of $107.5 \mathrm{dBA}$.

The OSHA allowable PEL for noise is a $100 \%$ dose or an 8-hour TWA of $90 \mathrm{dBA}$. The operator of the pump was not overexposed after 2.05 hours of operation and borderline for overexposure after 7.86 hours of operation. The lance operator was overexposed after 7.88 hours or operation. At these exposure levels, personnel would be required to be included in a hearing conservation program. Feasible engineering controls, administrative controls, and personal protective equipment (PPE-hearing protection devices) need to be used. The percentage of time spent at each loudness level (for the two significant exposures) that comprises the exposures can be seen in Appendix B. For the pump operator, $28.3 \%$ of the time the noise exposure was less than $85 \mathrm{dBA}$ which means that the majority of the time or $71.1 \%$ of the time the noise exposure was at sound levels above $85 \mathrm{dBA}$. For the lance operator, $21.637 \%$ of the time the noise exposure was less than $85 \mathrm{dBA}$ which means that the majority of the time or $78.363 \%$ of the time the noise exposure was at sound levels above $85 \mathrm{dBA}$. As can be seen on the graphs, the time spent over $85 \mathrm{dBA}$ for the lance operator was at a much higher decibel level than that for the pump operator. OSHA requires that a hearing conservation program be initiated if the 8 -hour TWA is $85 \mathrm{dBA}$.

During the 7.86 hours of operation for the pump operator, the noise levels were averaged for each one minute period of time and then an overall average of each one minute period was calculated which gave an average exposure level of $92.2 \mathrm{dBA}$ for an $80 \mathrm{~dB}$ cutoff level and $91.3 \mathrm{dBA}$ for a $90 \mathrm{~dB}$ cutoff level. The average exposure level for the lance operator was $107.5 \mathrm{dBA}$ for an $80 \mathrm{db}$ or a $90 \mathrm{db}$ cutoff level. OSHA requires an $80 \mathrm{db}$ cutoff for hearing conservation measurements and a $90 \mathrm{db}$ cutoff for engineering control compliance measurements. The maximum sound level observed during the measurement period was $108.6 \mathrm{dBA}$ for the pump operator and $121.9 \mathrm{~dB}$ for the lance operator and the highest instantaneous sound pressure level was $137.7 \mathrm{~dB}$ for the pump operator and $140.6 \mathrm{~dB}$ for the lance operator.

These measurements define noise as a significant exposure for personnel operating the Husky ${ }^{T M}$ pump and the waterjet lance. It must also be noted that the equipment was being operated in an open outdoor environment at the time of the measurements and operation in an enclosed facility would have the potential to increase the noise level due to other influences such as vibration and reverberation, therefore, it is recommended that noise monitoring be conducted while the equipment is being operated in an enclosed environment. 


\section{HUMAN FACTORS INTERFACE}

The technologies being tested for concrete decontamination and decommissioning are targeted for alpha contaminated concrete, therefore, the equipment operator was dressed out in Anti-C (alpha radiation) PPE which included cloth suit, hood, inner and outer boots, inner and outer gloves, and full face air-purifying respirator while performing maintenance activities on the pump and lance. The only difficulty the operator had while conducting maintenance on the equipment when wearing Anti-C PPE was some visibility problems due to the full face respirator and a decrease in tactile sensation in the hands and fingers. In addition, the need to perform work in the Anti-C PPE caused some increase in heat stress for the operator.

The lance operator was dressed out in Saranex coated Tyvek with a hood, hard hat, inner and outer gloves, and steel toed rubber work boots, and full face respirator during operation. Problems encountered included decreased visibility due to the full face respirator and an increase in heat stress. As would be expected, heat stress was a greater problem in a Saranex coated suit than in the Anti-C ensemble. The operator was then dressed out in a splash suit, inner and outer gloves, steel toed rubber work boots, hard hat, safety glasses, and face shield. Again the main problem during operation was decreased visibility, this time due to the face shield becoming fogged and sprayed with water and contaminant. There was also an increase in heat stress again greater than in the Anti-C ensemble.

If the concrete being decontaminated had contamination other than or in addition to alpha radiation, additional levels of protection, such as level A or level B PPE, may be required for the operator. These may create additional human interface problems such as a greater decrease in visibility and manual dexterity, an increase in heat stress, and an overall increase in physical stress. It is recommended that additional safety and health evaluations be conducted utilizing these higher levels of protection.

\section{EMERGENCY RESPONSE/PREPAREDNESS}

The ultra high pressure waterjet system would not be applicable for use in an emergency response situation.

Before emergency response is initiated into an area where the ultra high pressure waterjet is being used, complete shut down of the system needs to occur. Other hazards associated with the location of its use at a hazardous waste clean up site need to be considered. This might include alpha radiation, explosive atmospheres, or unknown contaminants. All appropriate monitoring and routine precautions for a hazardous waste site need to be taken into consideration. 
Emergency response/preparedness planning and training for a site would need to take into consideration not only routine emergencies that could be associated with an worksite but special consideration needs to be given to credible emergencies that could be encountered due to the high pressure water, diesel engine, and compressed air. Foreseeable injuries from the high pressure water jet could include severe lacerations and amputations.

If the Husky ${ }^{\top M}$ has been used indoors, monitoring for $\mathrm{O}_{2}$ before entry would be an essential function.

\section{SECTION 4 TECHNOLOGY APPLICABILITY}

Upon observation the technology did not produce any visible dust in the atmosphere and air monitoring did not show a significant dust level, as anticipated, due to the wet environment associated with this technology. The waterjet did however, create a situation where grit (small pieces of blasted concrete) was sprayed up to fifty feet from the point where the waterjet was in contact with the concrete. The water spray and the spray of concrete created a spread of contaminant that was evident on other surfaces and the PPE of the operator. The flying pieces of concrete presented a severe eye hazard. A splash suit or a water resistant Anti-C suit would not provide enough protection against puncture from flying debris. A Saranex coated Tyvek or a level B PVC suit may be required. In addition, safety glasses may not be protective enough and goggles need to be worn under the face shield.

After the water dries the debris that has been spread by the water spray can become a dust covering on the surface which if disturbed (especially in an enclosed environment) could become an airborne contaminant and therefore, an inhalation hazard.

The water lance would not be difficult to decontaminate and the hoses would be and could be considered consumables at the completion of the project. The Husky ${ }^{\mathrm{TM}}$ was designed to operate outside of the contaminated environment and would be difficult to decontaminate if circumstances required it be in the exclusion zone. The Husky ${ }^{\mathrm{TM}}$ would need to be torn down to decontaminate and this will not necessarily guarantee that decontamination for alpha will be complete and it will be difficult to survey for alpha contamination due to all of the small hard to reach (with a probe) spaces inherent in the equipment. 


\section{- SECTION 5 \\ REGULATORY/POLICY ISSUES .}

The site safety and health personnel where the ultra high pressure waterjet technology is being used need to be concerned with safety and health regulations applicable to the issues discussed above. Regulations that apply may be divided into four categories.

Core requirements are those regulations that would apply to any hazardous waste work site, regardless of the type of job. Technology specific requirements are those regulations that apply due to the specific technology being used. Special requirements are standards and policies that are specific to the technology itself and are required by reference in a regulation. Best management practices are not required but are recommended by organizations such as the American National Standards Institute (ANSI), the National Institute of Occupational Health and Safety (NIOSH), Department of Energy (DOE), National Fire Protection Association (NFPA), etc. These regulations/standards may include but not be limited to the following:

\section{Core requirements:}

- OSHA 29 CFR 1926.25 Housekeeping

- OSHA 29 CFR 1910.141 Sanitation (1910.141(a)(3) covers housekeeping)

- OSHA 29 CFR 1926.53 lonizing Radiation

- OSHA 29 CFR 1910.96 lonizing Radiation

- OSHA 29 CFR 1926 Subpart Z Toxic and Hazardous Substances

- OSHA 29 CFR 1910 Subpart Z Toxic and Hazardous Substances

- OSHA 29 CFR 1926.59 Hazard Communication

- OSHA 29 CFR 1910.1200 Hazard Communication

- OSHA 29 CFR 1926.64 Process Safety Management of Highly Hazardous Chemicals

- OSHA 29 CFR 1910.119 Process Safety Management of Highly Hazardous Chemicals 
- OSHA 29 CFR 1926.65 Hazardous Waste Operations and Emergency Response

- OSHA 29 CFR 1910.120 Hazardous Waste Operations and Emergency Response

- OSHA 29 CFR 1926.23 First Aid and Medical Attention

- OSHA 29 CFR 1910.151 Medical Services and First Aid

- Occupational Safety and Health Act 1970(5)(a)(1) General Duty Clause

Technology specific requirements:

- OSHA 29 CFR 1926 Subpart K Electrical

- OSHA 29 CFR 1910 Subpart S Electrical

- OSHA 29 CFR 1910 Subpart O Machinery and Machine Guarding

- OSHA 29 CFR 1910.147 The Control of Hazardous Energy (Lockout/Tagout)

- OSHA 29 CFR 1926.52 Occupational Noise Exposure

- OSHA 29 CFR 1910.95 Occupational Noise Exposure

- OSHA 29 CFR 1926.103 Respiratory Protection

- OSHA 29 CFR 1910.134 Respiratory Protection

- OSHA 29 CFR 1926.102 Eye and Face Protection

- OSHA 29 CFR 1910.133 Eye and Face Protection

- OSHA 29 CFR 1926.28 Personal Protective Equipment

- OSHA 29 CFR 1910.132 General Requirements (Personal Protective Equipment)

- ACGIH Threshold Limit Values for Chemical Substances and Physical Agents and Biological Exposure Indices 


\section{Best Management Practices:}

$-\quad$ ANSI S3.34-1986 Guide for the Measurement and Evaluation of Human Exposure to Vibration Transmitted to the Hand

$-\quad$ ANSI S3.18-1979 Guide for the Evaluation of Human Exposure to Whole-body Vibration

In addition to the above regulations and policies, it is imperative that all workers have appropriate and adequate training for the task and associated safety and health conditions. Training that would be required may be divided into four categories. Core training is that which is required for anyone entering a hazardous waste site to perform work, regardless of the type of job. Technology specific training is that training that is specific to the technology and required by safety and health standards. Special training is that which is specific to the technology to assure the worker is adequately trained for the task but is not necessarily required by safety and health standards. Best management practices are trainings that while not mandated by health and safety standards, provide information and knowledge to the worker that will allow the worker to perform his/her job safely. Training to be applied for the ultra-high pressure waterjet may include but not be limited to:

\section{Core training requirements:}

HAZWOPER (Hazardous Waste Operations and Emergency Response)

HAZCOM (Hazard Communication)

- Radiation Safety (Radiation Worker Training) for radiation sites

\section{Technology Specific Training:}

- Respiratory Protection

- Hearing Conservation

- Personal Protective Equipment

- Electrical Safety

Lockout/Tagout 


\section{Special training:}

Job specific training for equipment operation

\section{Best Management Practice training:}

- Ergonomics (proper lifting, bending, stooping, kneeling, arm-hand vibration, whole-body vibration

- Heat stress (learning to recognize signs and symptoms)

Working with and around high pressure water systems

- CPR/First Aid/Emergency Response/Bloodborne Pathogens

- Hand Signal Communication

- Construction Safety (OSHA 500) and or General Industry Safety (OSHA 501)

\section{SECTION 6 \\ OPERATIONAL CONSIDERATIONS \& RECOMMENDATIONS}

Recommendations made here for improved worker safety and health take into consideration the operation of the Husky ${ }^{\mathrm{TM}}$ and the waterjet lance. Specific recommendations include:

- It needs to be assured that workers are aware of the tripping hazards associated with the hoses that are necessary to operate the equipment. In addition keeping these as orderly as possible in compliance with good housekeeping regulations will help avoid injury due to tripping.

- The operators of the equipment need to have training in ergonomics to assure proper techniques in lifting, bending, stooping, twisting, etc. during equipment operation. The waterjet lance presented the most ergonomic problems due to the stooped position the operator had to assume during operation in spite of using the longest wand available. The weight of the lance was of concern due to its ability to increase upper body/arm fatigue. The lance design needs to be evaluated for the length and weight. Mounting the lance on a frame that would allow for remote operation would reduce several of the ergonomic problems associated with its use.

- The waterjet operator was subjected to arm-hand vibration while operating the equipment. The support handle on the lance was constructed of a hard rubber 
material. This placed increased stress on the hand. A softer material would place less pressure on the hand. The trigger on the lance for the waterjet was made of metal and was designed for single finger operation. This will put stress on the index finger and could lead to problems such as trigger finger. A trigger design that uses several fingers and a soft material over the metal would be a better choice.

The Husky ${ }^{\mathrm{TM}}$ pump operator was subjected to whole-body vibration in part due to the type of platform on which it was located. The platform on which the pump will be located during a job needs to be considered for this. The platform and the pump also need to be evaluated for anti-vibration engineering controls.

The Husky ${ }^{\mathrm{TM}}$ pump did not require the operator to be with it at all times to continue running. The operator was able to walk away from the pump and then periodically check the gauges and operating conditions. This could lead to more hazardous conditions for the lance operator. If a situation occurs where the pump needs to be shut down immediately, the pump operator would not be able to quickly hit the emergency stop button. The pump operator needs to stay with the equipment at all times when the lance is in operation.

- During the testing demonstration the Husky ${ }^{\mathrm{TM}}$ pump was located on an elevated platform (truck bed) which did not have side rails. Anytime the pump is located on an elevated platform, there is the potential for a fall to below hazard. The platform needs to have side rails and any ladders leading to the platform need to have hand rails to allow three points of contact to be maintained while climbing.

- The waterjet sprayed grit (small pieces of blasted concrete) and water up to fifty feet away. This not only has the potential to spread contaminant but the flying pieces present an eye and general struck by hazard. The operator may need PPE that provides further protection than that afforded by Anti-C. A Saranex coated Tyvek or level B PVC suit may be needed and goggles instead of safety glasses.

- The concrete debris and water that were sprayed during operations caused the concrete surface and adjoining concrete surfaces to become very slippery. This could lead to a bad fall with severe injuries. Workers must be aware of this hazard and avoid it by walking around these areas when possible.

- The spray may also cause contamination to be spread along with the water and debris. This will need to be evaluated on a case by case, job by job basis.

Noise exposure was significant during operation of the technology. Since testing was done in an outdoor environment, it is plausible that the noise levels would 
increase in an enclosed environment. The equipment needs to be evaluated for possible engineering controls to help decrease the noise exposure to the operator. If engineering controls are not possible, administrative controls, and/or adequate hearing protection must be incorporated during operation.

Due to the windy outdoor environment in which the testing demonstration was conducted and therefore, the noise monitoring was conducted, it is recommended that further testing for noise exposure be conducted while the technology is used in an enclosed environment similar to environments in which it would be used at a hazardous waste clean-up site. This would also allow for a more thorough evaluation of the heat stress to be encountered while wearing the appropriate PPE.

It is also recommended that the operation and maintenance activities be evaluated while the operator is wearing level A and level B PPE since these levels may be needed in environments where the concrete contamination is mixed in nature or other than radiation.

The safety and health issues discussed throughout this report could be reduced and in some cases eliminated if this type of high pressure water jet technology could be designed to operate remotely. 


\section{APPENDIX A \\ REFERENCES}

Occupational Safety and Health Standards for General Industry, 29 CFR Part 1910, Occupational Safety and Health Administration United States Department of Labor, 1995

Occupational Safety and Health Standards for the Construction Industry, 29 CFR Part 1926, Occupational Safety and Health Administration United States Department of Labor, 1995

Threshold Limit Values (TLV's) for Chemical Substances and Physical Agents and Biological Exposure Indices (BEl's), American Conference of Governmental Industrial Hygienists, 1995-1996

ANSI 1986, Guide for the measurement and evaluation of human exposure to vibration transmitted to the hand, New York, NY: American National Standards Institute, ANSI S3.34 


\section{APPENDIX B \\ IH SAMPLING DATA}

\begin{tabular}{|c|c|c|c|}
\hline \multicolumn{4}{|c|}{ 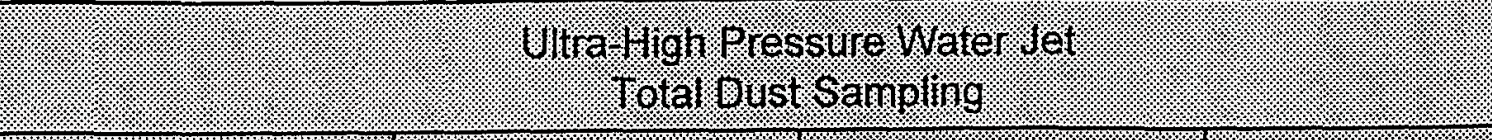 } \\
\hline Eate & Sample Nuringer & Analyte & resting \\
\hline $5 / 20 / 96$ & 052096-FIU-016 & Total dust & $2.0000 \mathrm{mg} / \mathrm{m}^{3}$ \\
\hline $5 / 20 / 96$ & 052096-FIU-017 & Total dust & $0.0000 \mathrm{mg} / \mathrm{m}^{3}$ \\
\hline $5 / 20 / 96$ & 052096-FIU-018 & Blank & $0.0000 \mathrm{mg} / \mathrm{m}^{3}$ \\
\hline $5 / 20 / 96$ & 052096-FIU-020 & Total dust & $84.103 \mathrm{mg} / \mathrm{m}^{3}$ \\
\hline $5 / 20 / 96$ & 052096-FIU-021 & Total dust & $0.2540 \mathrm{mg} / \mathrm{m}^{3}$ \\
\hline
\end{tabular}

* The OSHA PEL for total dust is $15 \mathrm{mg} / \mathrm{m}^{3}$ and the ACGIH TLV is $10 \mathrm{mg} / \mathrm{m}^{3}$. Current sampling was conducted for total dust. The need to sample for respirable dust and silica has to be considered during concrete decontamination and decommissioning activities. 


\section{NOISE SAMPLING}

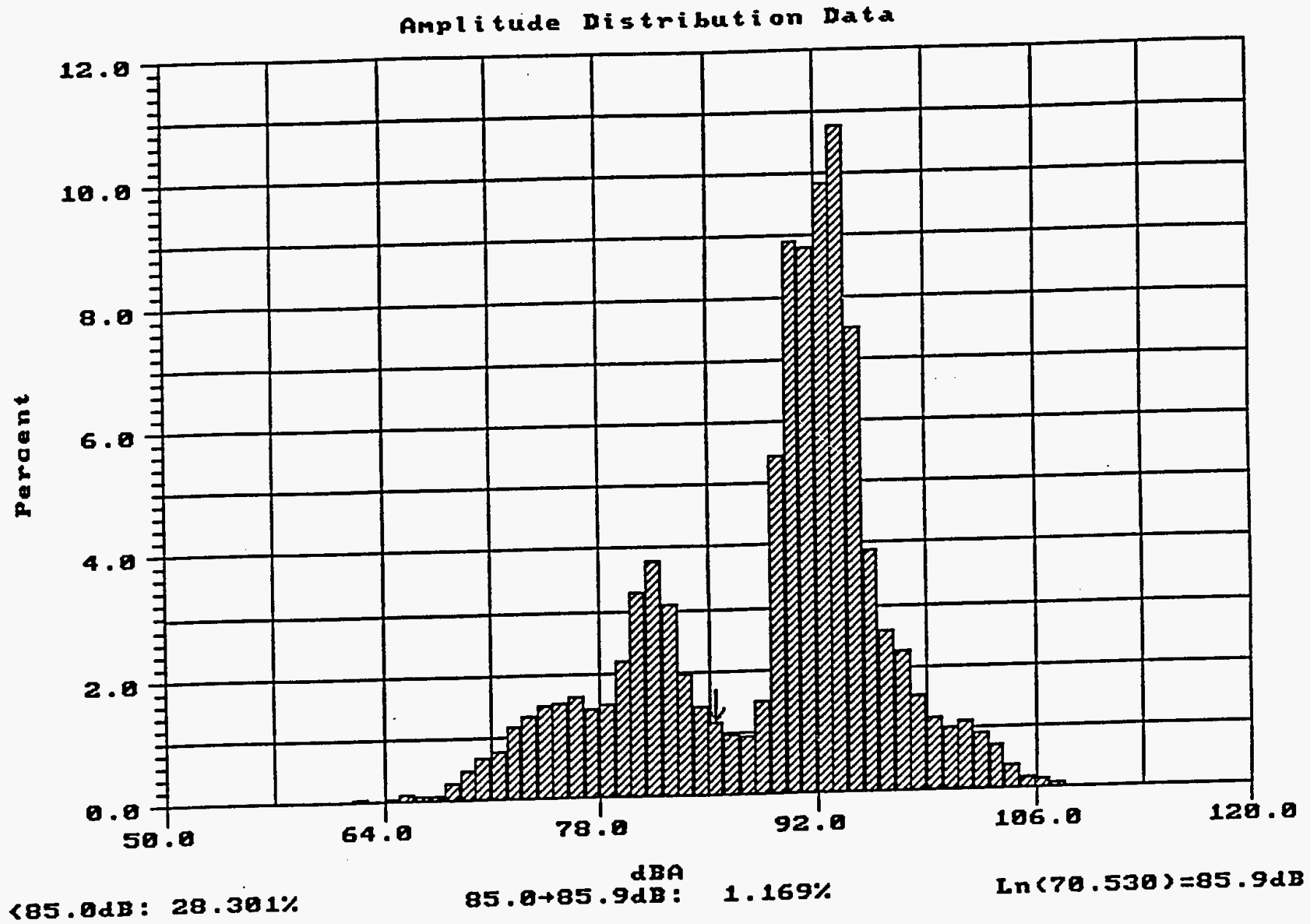

The above graph shows the distribution of noise for the Husky ${ }^{\mathrm{TM}}$ pump operator. The percentage of time spent at each decibel level can be obtained from the graph. As shown, $28.301 \%$ of the time the noise exposure was less than $85 \mathrm{dBA}$ which means that the majority of the time or $71.699 \%$ of the time the noise exposure was at sound levels above $85 \mathrm{dBA}$. OSHA requires that a hearing conservation program be initiated if the 8-hour TWA is $85 \mathrm{dBA}$. 


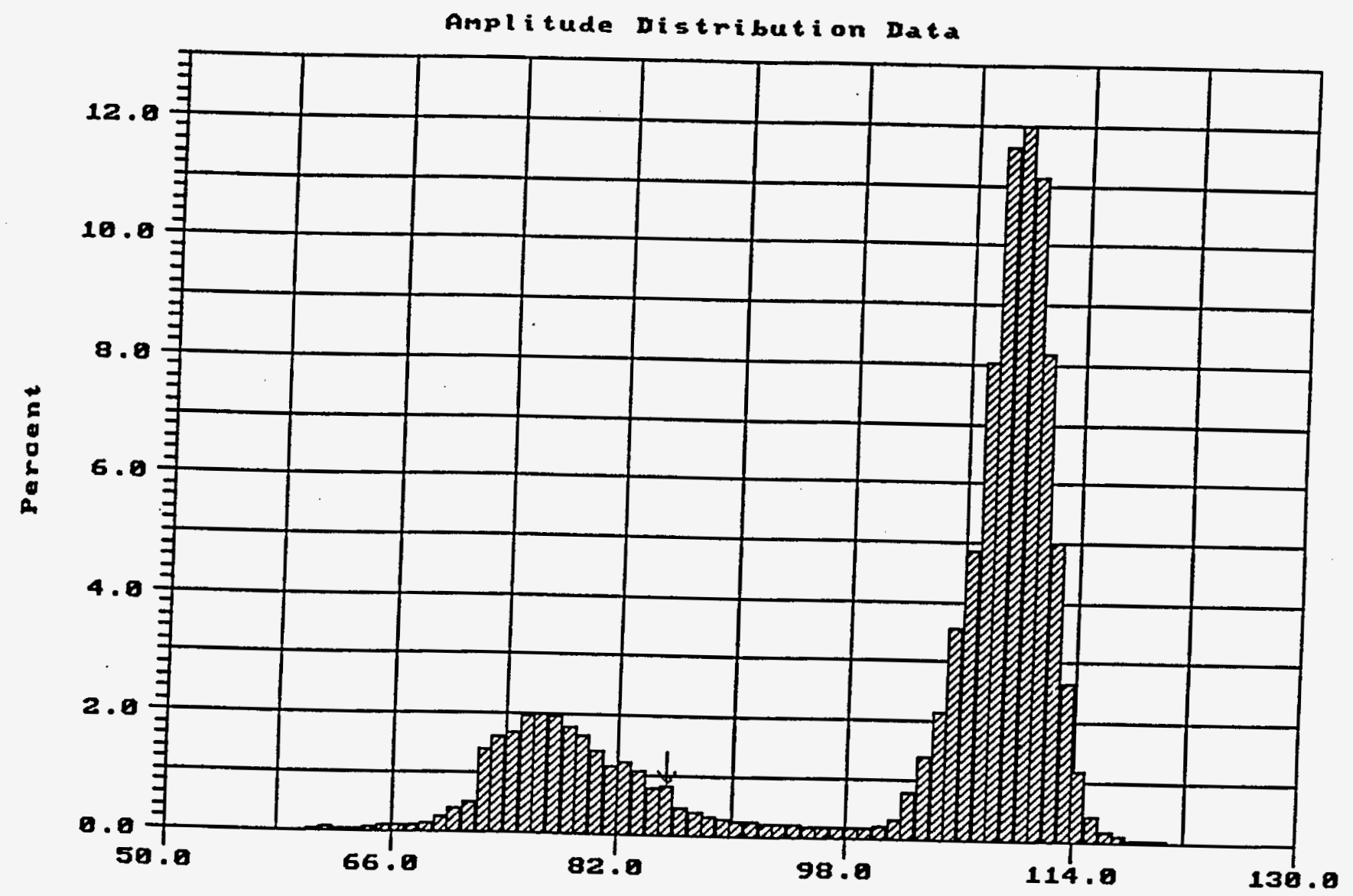

$<85.8 d B: 21.637 \%$

$85.8 \rightarrow 85$ dBA

$0.842 \%$

$\operatorname{Ln}(77.521)=85.9 d B$

The above graph shows the distribution of noise for the waterjet lance operator. The percentage of time spent at each decibel level can be obtained from the graph. As shown, $21.637 \%$ of the time the noise exposure was less than $85 \mathrm{dBA}$ which means that the majority of the time or $78.363 \%$ of the time the noise exposure was at sound levels above $85 \mathrm{dBA}$. OSHA requires that a hearing conservation program be initiated. 
Report Number (14) DOE/mC/32260--5841

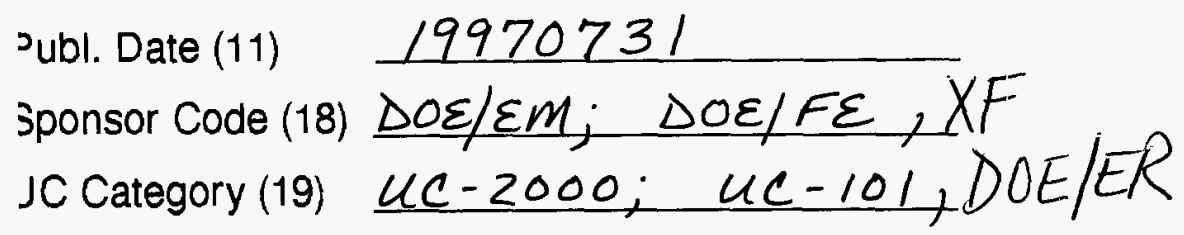

